\title{
Life Style Change and Reverse Cholesterol Transport in Obese Women
}

\author{
I. KRÁLOVÁ LESNÁ, P. SUCHÁNEK, J. KOVÁŘ, R. POLEDNE \\ Institute for Clinical and Experimental Medicine, Centre for Cardiovascular Research, Prague, \\ Czech Republic
}

Received June 18, 2009

Accepted July 14, 2009

\section{Summary}

HDL cholesterol resp. apolipoprotein A1 concentrations are tools to estimate individual CVD risk, although only a part of HDL particles participate in reverse cholesterol transport (RCT). This discrepancy was analyzed in life style change based on increase of physical activity and dietary counseling. Efflux of cholesterol from pre-labeled macrophages to plasma acceptors of tested individuals was used as an RCT measure. Changes of lipoprotein parameters, glucose, fasting insulin concentrations and RCT were analyzed in 15 obese women after 9-week intervention consisted of 5 sessions of increased physical activity per week. Controlled increase in physical activity for 9 weeks induced a decrease of body weight averaging $9 \mathrm{~kg}$ (ranged from 2.3 to $15.5 \mathrm{~kg}$ ). The intervention leads to significant decreases of triglycerides, apoprotein A1 and apoprotein B concentration, whereas total cholesterol, LDL cholesterol and HDL cholesterol did not change significantly. The increase of RCT was not significant, but there was highly significant negative correlation between individual decrease of body weight and an increase of RCT. Significant increase of RCT was found in 13 persons with a weight reduction more than $3.5 \mathrm{~kg}$. Substantial weight loss is necessary to increase RCT.

\section{Key words}

Reverse cholesterol transport • Cholesterol efflux • Lipoprotein metabolism $\bullet$ Life style modification

\section{Corresponding author}

I. Králová Lesná, Institute for Clinical and Experimental Medicine, Vídeňská 1958/9, 14021 Prague 4, Czech Republic. Fax: ++420241721574. E-mail: ivka@ikem.cz

\section{Introduction}

An increased risk of cardiovascular disease (CVD) in overweight and obese individuals is partly mediated by a low concentration of high density lipoproteins as the key biochemical feature of atherosclerosis is the accumulation of excess cholesterol in arterial intimal macrophages (Ross 1986). Although HDL particles display a spectrum of anti-atherosclerotic properties (anti-inflammatory, LDL oxidation protection, anti-apoptotic, antithrombotic, etc. (Von Eckardstein et al. 2001, Murphy et al. 2008)) their role in reverse cholesterol transport (RCT) from extrahepatic cells is probably the most important (Sviridov and Nestel 2002, Catalano et al. 2008).

Transfer of cholesterol excess from the cell is mediated by ABCA1, ABCG1 and SR-B1 cellular receptors. The monogenic defect (Tangier disease, Rust et al. 1999) as well as polygenic defects (Soro-Paavonen et al. 2007) of these receptors are able to influence RCT. On the other hand, RCT is also influenced by the capacity of intravasal acceptors - namely lipid poor HDL and large HDL particles - in different individuals and different statuses (Boadu et al. 2008, Marcel et al. 2008). It is very probable that for the majority of extrahepatic cells RCT is in equilibrium with LDL mediated transport to these cells and an increase of intravascular LDL concentration is accompanied by RCT acceleration (De Vries et al. 2005). A disequilibrium between the inflow of LDL cholesterol and its outflow from the cell leads to intracellular cholesterol cummulation. In monocytes located in the subendothelial space of arteries this cummulation is the main reason of their transformation into macrophages, residential macrophages and finally foam cells. This 
process plays a pivotal role not only in atherogenesis but also in stability of already formed cells. The reduced expression of specific receptors (Mauldin et al. 2008) is responsible for reduced RCT as well as the possible change of acceptors that might influence CDC risk in obese individuals (Marcel et al. 2008). In obese individuals, a high concentration of triglyceride rich lipoproteins which is also a common phenotype in these individuals might participate in regulation of RCT as it has been proven that triglyceride rich particles directly inhibit cholesterol efflux from human macrophage foam cells (Palmer et al. 2004).

Although data in the literature is partly conflicting, there is a majority opinion that adequately increased physical activity is able to increase HDL cholesterol and also probably apolipoprotein A1 concentrations (Kelley et al. 2004). We have documented that an intervention of life style of obese individuals is able to decrease the volume of abdominal as well as subcutaneous fat followed by decrease of proinflammation status and increased HDL cholesterol concentration (Dvořáková-Lorenzová et al. 2006). In this study, a similar life style change producing weight reduction by a combination of physical activity and dietary counseling was applied to analyze the possible role of weight reduction to the direct measurement of RCT as HDL concentration need not be simply related to cholesterol efflux (Soro-Paavonen et al. 2007).

\section{Methods}

\section{Subjects}

Fifteen healthy obese female volunteers were recruited through advertisements in life style magazines and healthy life style web sites. Inclusion criteria were: self motivation, under 40 years of age, BMI $>29$ and no apparent illness or medication. The design of the study was approved by Ethical Committee of the Institute of Clinical and Experimental Medicine and informed consent was obtained from all study subjects before the beginning of the study.

\section{Life style intervention}

A 9-week intervention consisted of 5 sessions of increase physical activity per week, at minimum 3 sessions were conducted under controlled conditions at a fitness centre and other two sessions (non controlled) of brisk walking or bicycling were performed usually at the weekend. Every session lasted 60 minutes. All participants obtained frequent dietary counseling based on their own 3-day dietary record. Substantial differences from the healthy diet (AHA) were identified in majority of subjects and it was successfully and positively influenced. Dietary counseling together with body weight record were repeated every second week throughout of the study.

\section{Clinical biochemistry parameters}

Blood specimens were obtained after $12 \mathrm{hrs}$ overnight fasting into a vacutainer tube at the beginning and at the end of the study after 9 weeks of intervention. After aggregation at room temperature, the serum was separated at 3500 RPM (10 minutes), portioned, frozen and stored at $-80{ }^{\circ} \mathrm{C}$. Aliquots of both serum were analyzed on the same day after whole experiment was completed. Concentration of triglyceride and total and LDL cholesterol were determined by Roche Diagnostica kits. HDL cholesterol was analyzed with the same kit after separation of apolipoprotein B containing particles by phosphotungstate method. Non-esterified fatty acids (NEFA) were measured by enzymatic test (Wako Chemicals GmbH., Neuss, Germany) and apoprotein A1 and apoprotein $\mathrm{B}$ by immunothurbidimetric method (Orion Diagnostica, Espoo, Finland). A Hitachi 920 autoanalyzer was used for all biochemical measurements and lipoprotein parameters and laboratory was under external quality control of CDC Atlanta, USA.

\section{Physical data}

Blood pressure was measured in a sitting position after 10 minutes rest and average of 3 measurements were used. Body weight was measured by calibrated balance with accuracy $\pm 0.1 \mathrm{~kg}$. Waist circumference was measured at the umbilicus area.

\section{Cholesterol efflux measurement}

RCT was measured in triplicate using in vitro macrophages pre-labeled with ${ }^{14} \mathrm{C}$ cholesterol (Perkin Elmer Life Sciences). THP1 human monocytes were seeded into 24 well plates at a density $2 \times 10^{5}$ cells $/ \mathrm{ml}$ and differentiated into macrophages by phorbol 12-myristate 13-acetate (100 ng/ml, Sigma Aldrich). Cholesterol efflux was analyzed after 240 min incubation in RPM1 medium containing $5 \%$ of serum of studied subjects as acceptor. Cholesterol efflux was measured between 15 and 240 $\min$. At the end of incubation, the media were centrifuged at $450 \mathrm{~g}$ at $4{ }^{\circ} \mathrm{C}$ to remove any floating cells and supernatant measured with scintillation liquid (described 
in details Poledne et al. 2009).

Medium free cells were twice washed with icecold PBS with $0.1 \%$ fatty acids free albumin. Cells were frozen for $1 \mathrm{hr}$ and then lyzed with isopropanol-hexan. Aliquot of extract was centrifuged at $440 \mathrm{~g}$, evaporated in scintillation vials and dissolved in scintillation liquid. Cholesterol efflux in \% was calculated as radioactivity in the efflux medium divided by total radioactivity of cells and media and multiplied by 100. Absolute differences in triplicate were $\pm 1.20 \%$ (S.D. 0.52), coefficient of variation of efflux essay was $9.8 \%$. The measurement of efflux was not corrected to efflux to albumin alone and then it might include also label carried by endogenously synthesized apolipoprotein E. This part of efflux should not vary within wells and individuals.

\section{Statistical method}

All results are expressed as mean \pm standard deviation. The difference between baseline data and data at the end of intervention were evaluated using a pair t-test. Correlation of parameters was analyzed by simple linear method.

\section{Results}

The life style intervention of 15 young obese women produced a substantial drop of body weight of more than $7 \mathrm{~kg}$ on average (Table 1). This decrease represents the change of body weight for almost $8 \%$ and it is very similar to our previous large study (DvořákováLorenzová et al. 2006). Unfortunately, in this present experiment we were able to detect much higher variability inside of this intervened group and maximal body weight decrease was $15.5 \mathrm{~kg}$ whereas on the other side one volunteer decreased her body weight only for 2.3 $\mathrm{kg}$ (after 9 weeks intervention consisting of increased physical activity and dietary change). It was not apparent from individual records of volunteers either for exercise sessions or of energy intake that differences in body weight reduction are related to any of these measures.

Body waist and hips circumference decreased highly significantly with a rather modest change of waist/hip ratio. These changes in anthropometric parameters were not followed by any significant decrease of non-esterified fatty acids whereas this parameter was significantly influenced by similar type of intervention in our earlier experiments (Dvoř́kováLorenzová et al. 2006).

Although insulin sensitivity analyzed as a
Table 1. Anthropometric parameters at the baseline and after intervention.

\begin{tabular}{lcc}
\hline & Baseline & $\begin{array}{c}\text { After life style } \\
\text { intervention }\end{array}$ \\
\hline Weight $(\mathrm{kg})$ & $91.73 \pm 9.57$ & $84.59 \pm 9.62^{*}$ \\
BMI $\left(\mathrm{kg} . \mathrm{m}^{-2}\right)$ & $33.18 \pm 2.03)$ & $30.57 \pm 2.07^{*}$ \\
Waist $(\mathrm{cm})$ & $101.94 \pm 7.7)$ & $95.31 \pm 7.18^{*}$ \\
Hip $(\mathrm{cm})$ & $118 \pm 5.96)$ & $112.53 \pm 5.13^{*}$ \\
\hline
\end{tabular}

Data are mean \pm S.D. * significantly different $p<0.0001$.

change of concentration of fasting insulin increased substantially at the end of experiment (Table 2), the decrease of fasting glucose concentration was only at the border line of statistical significance $(\mathrm{p}=0.056)$.

There were no significant changes either in the concentration of total cholesterol, LDL cholesterol or HDL cholesterol concentrations when baseline data were compared to data obtained at the end of intervention. On the contrary, there was a slight but significant decrease of both apoprotein B and apoprotein A1 concentration. These changes were related to change of total fat consumption calculated from dietary records (data not presented).

Cholesterol efflux increased only for less than 1 percentage point (i.e. $6.3 \%$ of baseline value) and this difference was not statistically significant (Table 2). A surprisingly very close correlation was found between the decrease of body weight and the individual change of cholesterol efflux after intervention. Volunteers with the smallest weight reduction also displayed the smallest change of cholesterol efflux after intervention (Fig. 1). Based on this information, an additional calculation was completed in which 2 volunteers with the lowest body weight change were excluded. When these two volunteers were omitted, cholesterol efflux increased for 1.8 percentage points (i.e. $14 \%$ of baseline value) and the calculated statistical significance of cholesterol efflux became significant (Table 2).

\section{Discussion}

Low physical activity and obesity have been shown to increase CHD risk and numerous studies have analyzed the effects of increased exercise and body weight reduction on the different levels of risk factors of premature atherosclerosis and CHD. The positive effects 
Table 2. Biochemical data at the baseline and after intervention.

\begin{tabular}{lccc}
\hline Total cholesterol (mmol/l) & $4.55 \pm 0.82$ & $4.26 \pm 0.67$ & $\mathrm{n} . \mathrm{s}$. \\
LDL cholesterol (mmol/l) & $2.90 \pm 0.78$ & $2.71 \pm 0.69$ & $\mathrm{n} . \mathrm{s}$. \\
HDL cholesterol (mmol/l) & $1.36 \pm 0.41$ & $1.33 \pm 0.39$ & $\mathrm{n} . \mathrm{s}$. \\
Triglycerides (mmol/l) & $1.59 \pm 0.76$ & $1.33 \pm 0.57$ & $\mathrm{p}<0.05$ \\
Apoprotein B $(\mathrm{gr} / \mathrm{l})$ & $0.91 \pm 0.20$ & $0.83 \pm 0.19$ & $\mathrm{p}<0.05$ \\
Apoprotein Al $(\mathrm{gr} / \mathrm{l})$ & $1.41 \pm 0.35$ & $1.33 \pm 0.31$ & $\mathrm{p}<0.05$ \\
NEFA (mmol/l) & $0.79 \pm 0.39$ & $0.86 \pm 0.20$ & $\mathrm{n} . \mathrm{s}$. \\
Glucose (mmol/l) & $5.50 \pm 0.56$ & $5.19 \pm 0.31$ & $\mathrm{p}=0.055$ \\
Fasting insulin (U/l) & $10.12 \pm 3.40$ & $6.02 \pm 2.12$ & $\mathrm{p}<0.001$ \\
Lipoprotein lipase (mmolFFA/h/lPHP) & $2.31 \pm 0.81$ & $2.99 \pm 1.06$ & $\mathrm{p}<0.02$ \\
Cholesterol efflux I (\%) $n=15$ & $12.87 \pm 2.39$ & $13.68 \pm 1.89$ & $\mathrm{n} . \mathrm{s}$. \\
Cholesterol efflux II (\%) $n=13$ & $12.65 \pm 1.62$ & $14.42 \pm 1.42$ & $\mathrm{p}<0.05$ \\
\hline
\end{tabular}

Data are mean \pm S.D.

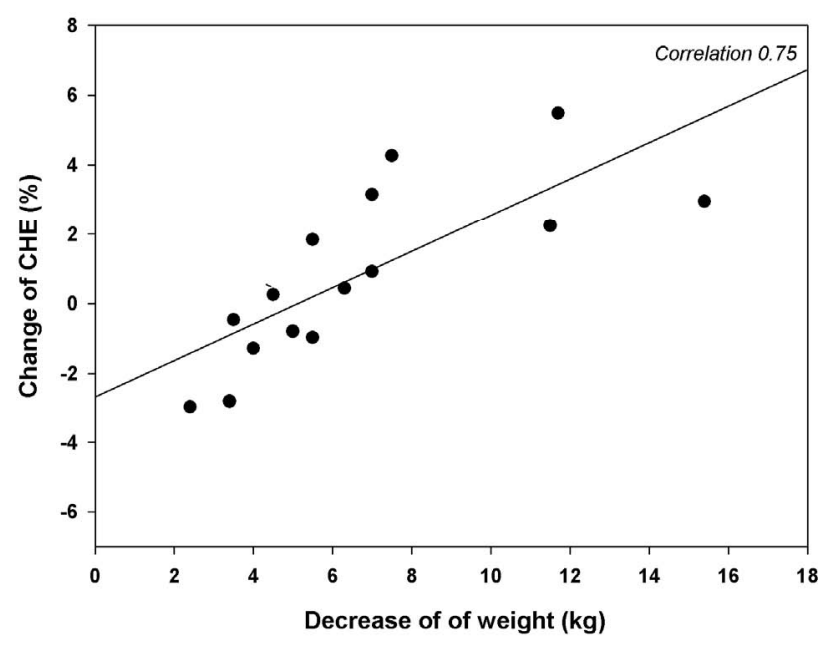

Fig 1. Relationship between the change of weight and change of cholesterol efflux (CHE) after nine weeks of intervention included increase in physical activity and switch to rational diet.

of this type of intervention are partly mediated by a change in lipoprotein profile. Different studies analyzing direct effect of exercise on HDL cholesterol or apoA1 concentrations have not consistently shown positive effects (Kelley et al. 2004). There is not general agreement on the effect of exercise on HDL concentration and composition of HDL particle size and their potential to clear an excess of cholesterol from extrahepatic cells. It has been suggested that long term endurance physical exercise is required to reach a significant increase of HDL cholesterol and apoA1 concentration (Williams et al. 1990).

Although a substantial and highly significant decrease in body weight as well as in other anthropometric parameters has been documented in this study there was no significant change of HDL cholesterol concentration. We suppose that the level of physical activity in our study was not sufficient to influence HDL concentration in spite of substantial decrease of body weight. Additionally, the total cholesterol and LDL cholesterol concentration were not changed. It must be considered that baseline data of our obese volunteers were in the normal range and are lower compared to a representative sample of the Czech population at the same age (data not shown) (Cífková et al. 2009).

Decrease of body weight by physical activity decreased significantly the fasting triglyceride concentration although it was also at the normal range at baseline. Our previous study shown that change of triglycerides after similar intervention differ in carriers of APOA5 gene (Suchánek et al. 2008) variants, nevertheless we did not determined genetic factors in this study. The significant decrease of triglycerides is in agreement with an increase of lipoprotein lipase activity, moderate decrease of fasting glucose concentration and a significant decrease of fasting insulin concentration. The effect of different level of physical activity on RCT has been documented in one study (Hoang et al. 2008), but on the contrary from the study presented, only the questionnaire data were used to compare to groups with different level of physical activity.

When the decrease of body weight and cholesterol efflux was correlated in all 15 volunteers, a highly significant correlation was found (Fig. 1). This might explain why an increase in RCT did not reached statistical significance. When data of two women with lowest change of body weight $(2.1$ and $3.2 \mathrm{~kg}$ respectively) were excluded, the difference between baseline and final mean of cholesterol efflux increased 
and became statistically significant (Table 2).

We should address comment on great differences of weight reduction between our subjects (from 2.3 to $15.5 \mathrm{~kg}$ ). There are three apparent possibilities for these differences: firstly different level of activities during two non-controlled session and during days without designed physical activities. Secondly we can suppose inter-individual metabolic differences, possibly in part genetic that may influence effect of our intervention. Thirdly we must admit that the diet was not fully controlled and subjects could differ in their compliance to dietary counseling.

It is possible to conclude that change of the life style of obese young individuals leads to decrease of body weight and waist and hip circumference. There was also a trend to increase the efflux of cholesterol from macrophages as a measure of RCT. Nevertheless, it is necessary to decrease body weight for more than 4-5\% to reach a biologically significant increase in RCT.

\section{Conflict of Interest}

There is no conflict of interest.

\section{Acknowledgements}

This study was partially funded by a Project NR 8486-4 Internal Grant Agency, Czech Ministry of Health, and by a Project 1M0510 Czech Ministry of Education, Youth and Sports.

\section{References}

BERROUGHI H, MAXIM I, CLOUTIER M, GRENIER G, KHALIL A: Age-related impairment of HDL-mediated cholesterol efflux. J Lipid Res 48: 328-336, 2007.

BOADU E, BILBEY NJ, FRANCIS A: Cellular cholesterol substrate pools for adenosine-triphosphate cassette transporter A1+dependent high-density lipoprotein formation. Curr Opin Lipidol 19: 270-276, 2008.

CATALANO G, DUCHENE E, JULIA Z, LE GOFF W, BRUCKERT E, CHAPMAN MJ, GUERIN M: Cellular SR-BI and ABCAl-mediated cholesterol efflux are gender-specific in healthy subjects. J Lipid Res 49: 635-643, 2008.

CÍFKOVÁ R, BRUTHANS J, ADÁMKOVÁ V, JOZÍFOVÁ $M$, GALOVCOVÁ M, WOHLFAHRT P, KRAJČOVIECHOVÁ A, LÁNSKÁ V: Longitudinal trends in major cardiovascular risk factors in the Czech population in1985 to 2007/8. Czech MONICA and Czech post-MONICA Study. Eur J Cardiol Prevent Rehabilit 16: S6, 2009.

DE VRIES R, KERSTENS MN, SLUITER WJ, GROEN AK, VAN TOL A, DULLAART RPF: Cellular cholesterol efflux to plasma from moderately hypercholesterolaemic type 1 diabetic patients is enhanced, and is unaffected by simvastatin treatment. Diabetologia 48: 1105-1113, 2005.

DVOŘÁKOVÁ-LORENZOVÁ A, SUCHÁNEK P, HAVEL PJ, STÁVEK P, KARASOVÁ L, VALENTA Z, TINTĚRA J, POLEDNE R: The decrease in C-reactive protein concentration after diet and physical activity induced weight reduction is associated with changes in plasma lipids, but not interleukin-6 or adiponectin. Metabolism 55: 359-365, 2006.

HOANG A, TEFFT CH, DUFFY SJ, FORMOSA M, HENSTRIDGE DC, KINGWELL BA, SVIRIDOV D: ABCA1 expression in humans is associated with physical activity and alcohol consumption. Atherosclerosis 197: $197-$ $203,2008$.

HOUMARD JA, BRUNO NJ, BRUNER RK, MCCAMMON MR, ISRAEL RG, BARAKAT HA: Effects of exercise training on the chemical composition of plasma LDL. Arterioscler Thromb 14: 325-330, 1994.

KELLEY GA, KELLEY K, TRAN ZV: Aerobic exercise and lipids and lipoproteins in women: a meta-analysis randomized control trials. J Women Healths 13: 1148-1164, 2004.

MARCEL YL, OUIMET M, WANG MD: Regulation of cholesterol efflux from macrophages. Curr Opin Lipidol 19: 455-461, 2008.

MAULDIN JP, NAGELIN MH, WOJCIK AJ, SRINIVASAN S, SKAFLEN MD, AYERS CR, MCNAMARA CA, HEDRICK CC: Reduced expression of ATP-binding cassette transporter G1 increases cholesterol accumulation in macrophages of patients with type 2 diabetes mellitus. Circulation May 27: 2785-2792, 2008.

MURPHY AJ, WOOLLARD KJ, HOANG A, MUKHAMEDOVA N, STIRZAKER RA, MCCORMICK SP, REMALEY AT, SVIRIDOV D, CHIN-DUSTING J: High-density lipoprotein reduces the human monocyte inflammatory response. Arterioscler Thromb Vasc Biol 28: 2071-2077, 2008. 
PALMER AM, MURPHY N, GRAHAM A: Triglyceride rich lipoproteins inhibit cholesterol efflux to (apo) apoliprotein A1 from human macrophage foam cells. Atherosclerosis 173:27-38, 2004.

POLEDNE R, STÁVEK P, PIŤHA J, BAUMGARTNER M, OMÁČKA A: Effect of exercise on LDL particle size. Cor Vasa 40: 217-221, 1998.

POLEDNE R, KRÁLOVÁ LESNÁ I: Direct method of reverse cholesterol transport measurement. Klin Biochem Metab 17: 96-99, 2009.

ROSS R: The pathogenesis of atherosclerosis: an update. $N$ Engl J Med 314: 488-500, 1986.

RUST S, ROSIER M, FUNKE H, REAL J, AMOURA Z, PIETTE JC, DELEUZE JF, BREWER HB, DUVERGER N, DENÈFLE P, ASSMANN G: Tangier disease is caused by mutation in the gene according ATP-binding cassette transporter 1. Nat Genet 12: 352-355, 1999.

SORO-PAAVONEN A, NAUKKARINEN J, LEE-RUECKERT M, WATANABE H, RANTALA E, SODERLUND S, HIUKKA A, KOVANEN PT, JAUHIAINEN M, PELTONEN L, TASKINEN MR: Common ABCA1 variants, HDL levels, and cellular cholesterol efflux in subjects with familial low HDL. J Lipid Res 48: 1409$1416,2007$.

SUCHÁNEK P, LORENZOVÁ A, POLEDNE R, HUBÁČEK JA: Changes of plasma lipids during weight reduction in females depends on APOA5 variants. Ann Nutr Metab 53: 104-108, 2008.

SVIRIDOV D, NESTEL P: Dynamics of reverse cholesterol transport; protection against atherosclerosis. Atherosclerosis 161: 245-254, 2002.

VOGT L, LAVERMAN GD, VAN OL A, GROEN AK, NAVIS G, DULLAART RP: Cellular cholesterol efflux to plasma from proteinuric patients is elevated and remains unaffected by antiproteinuric treatment. Nephrol Dial Transplant 21: 101-106, 2006.

VON ECKARDSTEIN A, NOFER JR, ASSMANN G: High density lipoproteins and arteriosclerosis. Role of cholesterol efflux and reverse cholesterol transport. Arterioscler Thromb Vasc Biol 21: 13-27, 2001.

WANG X, LIAO D, BHARADWAJ U, LI M, YAO Q, CHEN CH: C-reactive protein inhibits cholesterol efflux from human macrophage-derived foam cells. Arterioscler Thromb Vasc Biol 28: 519-526, 2008.

WILLIAMS PT, KRAUSS RM, VRANIZAN KM, WOOD PDS: Changes in lipoprotein subfractions during dietinduced and exercise-induced weight loss in moderately overweight men. Circulation 81: 1293-1304, 1990.

WILSON PR, ABBOTT RD, CASTELLI WP: High density lipoprotein cholesterol and mortality. The Framingham Heart Study. Arteriosclerosis 8: 737-741, 1988. 